Chapter 27

\title{
Comparative Studies Involving Transgenic and Non- Transgenic Soybean: What is Going On?
}

\author{
Marco Aurélio Zezzi Arruda, \\ Ricardo Antunes Azevedo, \\ Herbert de Sousa Barbosa, \\ Lidiane Raquel Verola Mataveli, \\ Silvana Ruella Oliveira, \\ Sandra Cristina Capaldi Arruda and \\ Priscila Lupino Gratão
}

Additional information is available at the end of the chapter

http://dx.doi.org/10.5772/52212

\section{Introduction}

There is no doubt that soybean [Glycine max (L.) Merrill] has a global importance with widespread applicability (food, biodiesel, secondary metabolites, among others) and economic value of its products in the global market [1] (ca. US\$ 38.9 billion is the estimated crop value in 2010 [2]). In terms of crop production, USA and Brazil occupy the first and second position in the world, with ca. 83 and 70 million ton, respectively [3]. These facts may explain the significant interest by biotechnological industries and research institutes in enhancing some characteristics of this crop such as nutrient quality, resistance to pests, and other subjects.

One of the most effective processes for attaining this task is the genetic modification, and clearly the one conferring resistance to glyphosate (the number one selling herbicide worldwide since the 80's [4]) is considered the main soybean genetic modification. This process involves the insertion of a gene (cp4 EPSPS: 5-enolpyruvylshikimate-3 phosphate synthase), via biobalistic (acceleration of metallic particles recovered with genetic material), which is responsible to the production of cp4-EPSPS enzyme from Agrobacterium sp. Such enzyme confers tolerance to glyphosate (N-fosfometil glycine), once that this substance inhibits the action of 5-enolpyruvylshiquimate synthase - EPSPS enzyme, which is involved in the bio- 
synthesis of aromatic amino acids. Its inhibition provokes delay in the development of plants, amino acids unbalance, and death of plants [5]. As a consequence it is easy to rationalize that plants genetically modified can normally develop in the presence of this herbicide, being the excellent result obtained in terms of soybean crop production also attributed to the transgenic cultures used. Exemplifying, ca. 49 million hectares (60\% of the cultivated world area) are occupied nowadays by transgenic soybean culture [6].

In this way, our hypothesis is that the genetic modification itself is contributing for changing a variety of characteristics of this organism, producing alterations, in a cascade manner, to the metabolism. As a result of these modifications, the genetically modified soybean is apparently searching a new equilibrium as a living organism in nature.

In order to evaluate this hypothesis, our research group has been, for the last eight years, carrying out some comparative studies taking into account alterations in proteins, metalloproteins, metals and enzymes. Since the content of proteins in soybean seeds is high (ca. 40\%) [7], hundreds of proteins are expected to be found after a separation process, making our proposal a hard task. Then, the utilization of the most up-to-date analytical techniques presenting high resolution in terms of enzymes, proteomics and metallomics approaches is almost imperative.

In this chapter, the concept of plant stress is mainly one related to oxidative stress, followed by a variety of examples regarding soybean. Additionally, basic concepts of proteomics and metallomics will be described, followed by a compilation of the results from all strategies and techniques that we have been adopting along the period devoted to the study of transgenic soybean, which were utilized for corroborating our previous hypothesis. Other examples in the literature are also presented in order to support our data. Then, techniques based on bidimensional chromatographic and non-chromatographic protein separations (i.e. 2DHPLC, 2D PAGE), image analysis for protein expression evaluations (i.e. 2D DIGE), inorganic mass spectrometry for identification/quantification of metals (i.e. HR-SF-ICP-MS, ICP-MS, LA-ICP-MS), organic mass spectrometry for characterization of proteins (i.e. MALDI-QTOFMS, ESI-LC-MS-MS), and hyphenated techniques for improving the quality on protein information (i.e. 2D-HPLC-ICP-MS) will be also emphasized. In the end of this chapter, a section of future Trends is provided, putting in evidence, in our point of view, some other strategies to be adopted for an in-depth investigation of this transgenic crop.

Finally, it is important to stress that the main goal of this chapter, and also of our studies, is only to present those results found within a series of projects developed by our research group concerning transgenic soybean. Despite the awareness of a public disagreement about the cultivation and commercialization of transgenic soybean, this chapter does not have the intention neither to defend genetic modification nor to make any criticisms to it.

\section{Plant stress}

In this section we have decided to focus our attention on the antioxidant responses trigged by some key biotic and abiotic stresses that have more significant information available, based on recent publications. 
When oxidative stress is taken into account, it is interesting to mention firstly, the role of molecular oxygen $\left(\mathrm{O}_{2}\right)$ in our environment. Due to the presence of oxygen and its reactions, both positive and negative aspects inherent to the process can occur, which is called oxidative stress.

Among all planets in our solar system, Earth is the only one that contains $\mathrm{O}_{2}$, and the only one able to support aerobic life as the way that we understand its meaning. According to [8], the concentration of $21 \%(\mathrm{v} / \mathrm{v}) \mathrm{O}_{2}$ on Earth's atmosphere is derived from the photosynthetic activities of cyanobacterias and plants. The reference [9] commented that by an estimate, the total amount of $\mathrm{O}_{2}$ in the Earth is about $410 \times 10^{3}$ Erda moles and from this value, $38.4 \times 10^{3}$ Erda moles is in the water form. When the aerobic life is concerned, these authors commented that this specific style of life is responsible for the major portion of $\mathrm{O}_{2}$ turnover: photosynthesis is the main input of $\mathrm{O}_{2}$, and respiration the main output.

Oxygen is relatively non reactive, but in some situations (as normal metabolic activity or when under environmental disturbance), it is able to switch to an excited state, producing free radicals and similar forms [9-10]. Then, it is clear in this scenario that adaptation processes to environmental changes are crucial for plant growth and survival. In view of its importance, it is interesting to remember the processes which lead to the reduction of molecular $\mathrm{O}_{2}$. According to [11] such processes occur following four steps and generate several $\mathrm{O}_{2}$ species. The first one requires an extra energy but the subsequent steps are exothermic, occurring spontaneously. The reaction products $\left(\mathrm{H}_{2} \mathrm{O}_{2} ; \mathrm{O}_{2}{ }^{*} ; \mathrm{HO}_{2}{ }^{-} ; \mathrm{OH}^{-}\right)$can act in different ways in the cellular environment.

Hydrogen peroxide is a relatively long-lived molecule and can diffuse from its site of production [12]. Beside this, its toxicity has long been known. The $\mathrm{O}_{2}{ }^{\bullet}$ radical half-life is short (2-4 $\mu \mathrm{s})$, but it is highly reactive and can form hydroperoxides and can oxidize histidine, methionine and tryptophan. When this radical is in the cellular environment, it causes lipid peroxidation as a consequence of oxidative deterioration of membrane polyunsaturated lipids. So, the hydrogen peroxide is not only toxic to cells, but in an extracellular medium it may react with transition metals, such as iron and copper, generating hydroxyls, which can cause cell damage. Beside this, when the levels of lipid peroxidation are higher (normally lipid peroxidation values are estimated by the concentration of malondialdehyde in samples) it suggests indirectly the establishment of a condition of oxidative stress. The hydroxyl radical $\left(\mathrm{OH}^{-}\right)$has a very strong potential and half-life of less than $1 \mu \mathrm{s}$, and as a consequence, it has very high affinity for biological molecules [13]. What is particularly interesting about these species is that all of them can be generated by molecular oxygen reduction and they may play roles as toxic molecules or they can be excellent candidates for events/studies involving plant cell signaling [8, 13-16].

In these terms, the production of reactive oxygen species (ROS) is generally described as harmful due to their potential to cause irreversible damage to photosynthetic components in plants. However, despite this potential in causing harmful oxidation, modulation of ROSantioxidant interaction plays a role in many stresses, as well as other responses to the environment. Additionally, this system can be considered as a powerful signaling process to molecules involved in the control of plant growth and development as well as priming accli- 
matory responses to stress stimuli [17-18]. In these terms, oxidative stress can be described as a central factor in abiotic and biotic stress that occurs due to imbalances in any cell compartment between the production of ROS and antioxidant defense [16, 19].

As indicated in [18] it is possible to verify that the pathways of ROS signaling are made by homeostatic regulation which can be achieved by the antioxidant redox buffering, making possible the determination of lifetime and the specificity of the ROS signal. It is interesting to emphasize that plants which demonstrate low activities for catalase (CAT) and cytosolic ascorbate peroxidase (APX), two key enzymes involved in the breakdown of $\mathrm{H}_{2} \mathrm{O}_{2}$, show less severe stress symptoms when compared to the ones where one of these enzymes is missing [20].

Talking about antioxidant defense systems, it can be attested that, in plants, the first line of defense against oxidative stress is the avoidance of ROS production [17] and once formed, ROS must be detoxified in order to either avoid or minimize eventual damages. In this way, the detoxification mechanisms can be considered as a second line of defense against the detrimental effects of ROS [21]. Beside this, some antioxidant enzymes can be considered as a second defense line against oxidative stress, since they act either as a catalyzer in ROS reaction or are involved in directing ROS processing [22]. The repair of oxidatively damaged proteins can be considered as the third line of defense against ROS [23].

According to [24] ROS species are commonly generated under stress conditions and due to its strong oxidative capacity, it acts on all types of biomolecules. In terms of the interactive effects of these species, it is possible to say that it can react with each other and with other molecules. For example, $\mathrm{O}_{2}{ }^{--}$may react with lipids peroxides or nitric oxide, leading to the formation of peroxynitrite, which is less reactive than peroxides. In the same context, [13] pointed out that plants may favor the formation of one or other reactive species by preferentially scavenging peroxide $\left(\mathrm{H}_{2} \mathrm{O}_{2}\right)$ with antioxidants or, in contrast, accumulating peroxide by the activation of superoxide dismutase (SOD).

The oxidative response in plants can be exacerbated by stressful conditions [16]. At the molecular level, the extent and nature of this response can differ among species and even among those closely related varieties of the same species. For example, 24 differentially expressed genes in soybean leaves were observed after glyphosate treatment when comparing tolerant and non tolerant soybean lines [25]. Therefore, oxidative responses are not only linked to the genetic expression. The reference [26] shows that some biochemical parameters (such as total soluble amino acid content and CAT activity in soybean roots) were also altered as a response to differential glyphosate application. The increase in the enzyme activities indicates ROS generation and a subsequent antioxidant response. Alterations in the antioxidative system of suspension-cultured soybean cells were observed [27], which were induced by oxidative stress using a peroxidizing herbicide (oxyfluorfen). Ascorbate and glutathione (non-enzymatic cellular antioxidants) showed different responses and the activities of some enzymes involved in cellular defense were also altered. For instance, peroxidase and catalase increased by $40-70 \%$ while glutathione S-transferase (GST) exhibited a 6-fold increase under oxyfluorfen stress. 
Stress-induced ROS accumulation is counteracted either by enzymatic oxidant systems that include a variety of scavengers, such as superoxide dismutase (SOD), ascorbate peroxidase $(\mathrm{APX})$, glutathione peroxidase (GPX), glutathione S-transferase (GST), and catalase (CAT), or by non enzymatic low molecular weight metabolites, such as carotenoids and flavonoids $[16,28-29]$. As an example related to the influence of the enzymatic machinery under a stress situation, the reference [30] pointed out that as a response to stress, plants may increase the activities of some enzymes such as glutathione S-transferase (GST), involved in the detoxification of xenobiotics. These authors also investigated in detail the mechanisms of interaction between the GST enzyme and its substrates, indicating that the information might help in the engineering of new GSTs with improved detoxification efficiency [30].

In the context so far referred, and particularly with soybean, which is the main focus of this chapter, molecular and biochemical studies have explored several aspects related to the manipulation of metabolic pathways towards adaptation responses which can help to mitigate oxidative stress.

If ROS scavenging pathways in plants are the main focus, the involvement of at least 3 cycles have to be considered: a) the water-water cycle in chloroplasts, including SOD; b) the ascorbate-glutathione cycle in chloroplasts, cytosol, mitochondria, appoplast and peroxisomes; and c) GPX and CAT in the peroxisomes [31]. The equilibrium between the production and the scavenging of ROS may be altered by biotic and abiotic stress factors such as UV radiation, temperature, air pollution, pathogen attack, heavy metals, nutrient deficiency, and herbicides, among others [32].

The clear understanding of the mechanisms by which some endogenous or exogenous agents can lead to plant toxicity and how plants answer to this specific situation, is essential. Besides this, understanding how toxicity occurs, what kind of alterations occur in plant structure and metabolism among other situations are important steps for genetic breeding programs, when searching for new varieties susceptible or tolerant to stress factors and even for bioremediation/phytoremediation programs [32].

Although there has been a rapid progress in recent years in the field of plant stress studies, there is a consensus among researches that there are still many uncertainties in understanding how effectively ROS affects the stress response of plants [32-33].

A short list of examples that will emphasize the detoxification mechanism involved in plant stress defense and a diversity of enzymes that can be involved in the dismutation of ROS is then presented. For example, soybean has been shown to be highly sensitive to ozone $\left(\mathrm{O}_{3}\right)$ and the oxidation of some proteins may cause alterations in the activities of enzymes across nitrogen and sulfur nutrient assimilation pathways linked to stress responses [34]. The chronic exposure to high $\mathrm{O}_{3}$ may lead to increased expression or oxidation of proteins, including APX, GSTs [34] and decrease the activities of monodehydroascorbate reductase (MDHAR) and glutathione reductase (GR) [35], indicating a fundamental role of these enzymes in stress response when soybean is subjected to $\mathrm{O}_{3}$. Furthermore, soybean submitted to chronic high $\mathrm{O}_{3}$ concentration and then exposed to an acute $\mathrm{O}_{3}$ stress provided evidence that there was an immediate transcriptional reprogramming that allowed for maintained or 
increased ascorbate (AA) content in plants grown at high $\mathrm{O}_{3}$ [36]. In another study using two tropical soybean varieties (PK 472 and Bragg) exhibiting differential sensitivity to $\mathrm{O}_{3}$, reference [37] showed that the CAT activity decreased whereas peroxidase increased in both varieties upon exposure to $\mathrm{O}_{3}$, but reflecting the greatest sensitivity of PK 472 in relation to the high magnitude of the reductions in the levels of antioxidants, metabolites and nutrients. Besides this, the damage $\mathrm{O}_{3}$ effects produced were found to be more prominent during the reproductive than the vegetative growth stage.

Although soybean plants have shown a positive and significant correlation between activity of antioxidant enzymes and the osmolyte proline (Pro) content to water deficit stress [38], the metabolic reasons associated with the differential sensitivity of soybean cultivars to water deficit stress are not well understood [39]. According to the authors, water deficit stress increased antioxidant enzyme activities of SOD, CAT and GPX more at mild than at high water deficit stress [39]. In addition, soybean plants have shown protective mechanisms associated to proline concentration and GR, APX, and CAT activities under salt stress [40].

The increase in soybean productivity has been also accounted to the development and widespread use of improved cultivars with increased resistance to stressful conditions. A promising technique for agricultural improvement in arid and semiarid areas is the use of a pretreatment of soybean dry seeds with a low dose of gamma rays (20 Gy) before planting, enhancing drought tolerance and minimizing the yield losses caused by a water deficit condition [41].Overall, application of a low dose of gamma irradiation (20 Gy) increased the activities of phosphoenol pyruvate carboxylase and ribulose-1,5-bisphosphate carboxylase/ oxygenase (RUBISCO) under drought stress, avoiding the destructive effects of water deficits on chloroplasts [41]. Furthermore, the manipulation of Pro can affect the (h)GSH, amino acids concentrations and APX activity, contributing to the detoxification of ROS in soybean subjected to simultaneous drought and heat stresses [42].

The regulation of thiol metabolism has become important for optimizing crop yield and quality of soybean [43]. The sulfur assimilatory pathway in soybean metabolism can be metabolized into molecules that protect plants against oxidative stress. The genetic manipulation of the cytosolic isoform of O-acetylserine sulfhydrylase (OASS), an enzyme involved in the sulfur assimilatory pathway, resulted in high levels of thiols and increased tolerance of plants to metal toxicity [44].

It is also important that information concerning changes in antioxidant capacity in immature seeds harvested at different reproductive stages [45], exhibited decreases in free radical scavenging activity and total antioxidant capacity with the advancement of maturity. This occurred concomitant with increased concentration of tocopherol and isoflavone isomers. Therefore, it is important to take into consideration that not only organs or tissues may present distinct responses to stress, but the plant stage of development is also important.

Reference [46] reported that different metals may act and induce different levels of copperzinc superoxide dismutase ( $\mathrm{Cu}-\mathrm{Zn} / \mathrm{SOD})$ expression in soybean plants exposed to $\mathrm{Cd}$ and $\mathrm{Pb}$. Also, $\mathrm{Cd}$ caused the induction of $\mathrm{Cu}-\mathrm{Zn} / \mathrm{SOD}$ mRNA accumulation for all $\mathrm{Cd}$ concentra- 
tions and $\mathrm{Pb}$-treated roots showed induction of these isoenzymes only at medium metal concentrations.

It is also important to bring into the scene of stressful condition for plants, the soil type used. In a recent work soybean exposed to $\mathrm{Cd}$ and $\mathrm{Ba}$ [47] showed that the activity of antioxidant enzymes can change depending on the soil type, time-length of exposure and metal concentration [47]. For instance, GR and SOD activities in the leaves of soybean plants grown in an Oxisol soil contaminated with Cd decreased over time, whilst remaining high in an Entisol soil. The changes of enzyme activities were mainly dependent on buffering capacity of the soils with the Entisol exhibiting a lower capacity, with the plants suffering higher oxidative stress than those plants grown in a clay soil such as presented by an Oxisol soil [47].

Moreover, it is also important to investigate the effect of stressful conditions in soybean productivity taking into consideration more than one environmental contaminant or stress factor in the same agricultural region. In this context, the combination of $\mathrm{Cd}$ and acid rain pollution damaged the cell membrane, decreased the activities of POX and CAT, showing a higher potential threat to soybean seed germination than the single separate effect of each contaminant [48]. In another study, a correlation between the rate of ROS generation and antioxidant enzyme activities was established under hypoxia and high $\mathrm{CO}_{2}$ concentration [49]. The CAT activity in soybean plants increased during the first hours of hypoxia whereas peroxidase activity started to play a more key role in cell defense only after a longer exposure to hypoxia. In this study, the processes of ROS accumulation and antioxidant enzymes were induced by the higher $\mathrm{CO}_{2}$ content, indicating that $\mathrm{CO}_{2}$ can switch on plant adaptation to hypoxic stress [49].

Another interesting study involving the combination of distinct stressor agents was carried out by combining $\mathrm{Al}$ and $\mathrm{Cd}$ with both leading to synergistic effects on plant growth and antioxidant responses in two soybean cultivars with different Al tolerance levels [50]. According to the authors, the $\mathrm{Al}$ treatments and low $\mathrm{pH}$ value (4.0) caused reduction in chlorophyll content and net photosynthetic rate, leading to growth reduction. The increased SOD and peroxidase activities were detected in the plants submitted to both metals, especially in the Al-sensitive cv. Zhechun 2, which also exhibited significantly higher $\mathrm{Al}$ and $\mathrm{Cd}$ contents than the Al tolerant cv. Liao-1. Moreover, $\mathrm{Cd}$ supplementation increased $\mathrm{Al}$ content in the plants exposed to $\mathrm{Al}+\mathrm{Cd}$ stress [50]. Such an observation confirms another key aspect that should receive attention which is how the elements of the soil interact and can define an uptake profile by the plant root system possibly resulting in an induction of stress condition. Such studies are also of the upmost importance when considering the use of phytoremediation as a technique to recover a contaminated soil.

Similarly, studies about the interactions between plant roots and beneficial metal-tolerant microorganisms are gaining importance and may be an important approach to be considered in studies about plant adaptation and alleviation to a variety of environmental stresses [51]. For example, soybean plants inoculated with arbuscular mycorrhizal (AM) fungi showed reduced MDA content and increased APX activity to the oxidative stress generated by paraquat (PQ) [52]. In another study, activities of SOD and peroxidase were increased in the shoots of soybean plants with mycorrhizal $(\mathrm{M})$ fungi grown under 
$\mathrm{NaCl}$ salinity [53]. Once again, a more integrated view is needed and deserves attention. These two studies commented above indicate the importance of mycorrhizal fungi regulation as a general strategy to protect plants from stress. If soil type is added to this equation, a much more complex situation is created and such an integrated study reflects the reality of many agronomic situations. This also raises the question over the use of hydroponic systems to study oxidative stress in plants, particularly when induced by non-essential elements, since it is not necessarily the real field condition. Yet, is not our intention to say that such studies under hydroponic conditions are not important. On the contrary, they also have advantages. However, a more dynamic or integrated type of study should be considered in our point of view.

Curiously, grafting, which is a well-known agronomic technique largely used in agriculture, has not been used much in studies of stress in plants. The grafting technique has a tremendous potential to add further important understanding about stress signaling, assimilation, transport and accumulation of metals, opening a new perspective to study these grafted plants at the biochemical and molecular levels. Unfortunately, very few examples are available in the literature focusing on the investigation of plant stress responses. An example of such a study is the one carried out by [54] who showed that Cd seed concentration can be influenced by the difference in translocation of $\mathrm{Cd}$ from soil to the seed and in $\mathrm{Cd}$ accumulation capacity of roots among soybean cultivars by the use of grafting.

Nowadays, the development of plant manipulation techniques, for example the production and use of transgenic plants, has contributed to studies involving plant antioxidant responses induced either by exogenous or endogenous factors (such as herbicide, metals, pollution). Studies involving the mechanisms leading to stress-tolerant plants are important and needed, since they can aid understanding and create new possibilities for the use of these kinds of plants. The knowledge provided by the "omics studies" such as proteomics, metabolomics, metallomics and genomics, added to enzymatic evaluation, can provide information that can decisively help in answering many questions related to oxidative stress and ROS control [32].

Taking into account the importance of "omics" platforms, as well as their use for corroborating our initial hypothesis, the following sections will focus on these important strategies. They will be divided into proteomics and metallomics, with brief descriptions of each one, as well as some discussions and examples regarding transgenic cultures, but always concentrating the focus on soybean.

\section{Proteomics}

Proteomics can be defined as the large-scale study of proteins, including not only their identifications and quantifications, but also the determination of their localizations, modifications, interactions, activities, and functions [55]. This information is extremely important to evaluate interactions between different proteins, or between proteins and other molecules, and may reveal the functional role of proteins [56]. In this sense, proteomics is an important 
part of plant science, providing essential tools for understanding the functions of many plant-specific biological processes at the molecular level [57]. Currently, plant proteomic studies are focused on understanding the impact of different conditions of plant physiology such as the characterization of plant defense under biotic and abiotic stress [58,59], the characterization of subcellular, cellular or plant organ proteomes [60-61], the characterization of genetic modifications [62-63], as well as others.

The insertion of exogen DNA fragments into the DNA of the target organism, to confer some enhanced characteristics to the latter, describes the process termed genetic modification [64]. Focusing on plants, improved productiveness, enhanced tolerance to herbicides, synthesis of new substances and others can have consequences related to genetic modification [64]. The natural responses to this process are known to change the protein map of an organism [65]. In this sense, comparative proteomics become the strategy of choice, being useful for establishing qualitative and quantitative differences between genetically and nongenetically modified organisms [66]. In this way, studies of protein changes are frequently carried out through polyacrylamide gels by evaluation of their images, providing relevant information for comparative proteomic studies $[67,68]$ as well as using appropriate mass spectrometric techniques for evaluating the identity of the studied proteins [69-70].

For proteomic studies, gel electrophoresis separations are the most used platform, due to their high resolution, allowing either high efficiency protein separation or the identification of potential protein spots with differences in concentration or expression in the gels evaluated $[67,68]$. The gel electrophoresis technique can be applied in proteomic studies as follow: (1) one-dimensional gel electrophoresis (SDS-PAGE) [71], (2) two-dimensional gel electrophoresis (2-D PAGE) followed by manual image analysis [66] and (3) two-dimensional difference gel electrophoresis (2-D DIGE) followed by automatic image analysis [72]. The application of these techniques in comparative studies involving transgenic soybeans has been little explored, where variation of different proteomic profiles in soybean genotypes [73], abiotic environmental stress [74], osmotic stress [75] and improvement of protein quality in transgenic soybean plants [76] are examples found. In this way, the use of these separation techniques in combination with mass spectrometry were applied in our research group to comparative proteomic studies in transgenic and non-transgenic soybean seeds, and it will be discussed below.

\section{One-dimensional gel electrophoresis (SDS-PAGE)}

The separation of the proteins using SDS-PAGE technique is based on their molecular mass, covering a broad separation range [67]. In our research group, this technique was used with mass spectrometry (ESI-QTOF MS/MS) for the identification of the enzyme cp4 EPSPS, in order to prove that the soybean in question was genetically modified. For this task, the protein band corresponding to a mass of $47 \mathrm{kDa}$ was cut, the proteins reduced, alkylated, and subjected to two enzymatic digestion protocols: trypsin and chymotrypsin. 
As a result, the enzyme cp4 EPSPS was identified using the SDS-PAGE technique and using either trypsin or chymotrypsin as a cleavage enzyme. However, trypsin showed the best results in terms of score and coverage (as a percentage). Moreover, the enzyme was identified in the database containing sequences from the soil bacterium Agrobacterium sp, the origin of the gene used in genetic modification. This method proved to be simple and very efficient, without needing sample prefractionation using chromatographic columns [77].

\section{Two-dimensional gel electrophoresis: 2-D PAGE}

In 2-D PAGE technique, the proteins are first separated on the basis of their net charges by isoelectric focusing (IEF) and then separated on the basis of their molecular mass by polyacrylamide gel electrophoresis in the presence of sodium dodecyl sulfate (SDS) [67].

The combination of 2-D PAGE and mass spectrometry is one excellent strategy to obtain proteomic maps [78]. Furthermore, taking into account that we were finding some differential proteins when investigating transgenic and non-transgenic soybean seeds, this technique showed itself to be excellent for this task. In this sense, our experience in terms of this kind of study will be commented.

Reference [79] used the combination of 2-D PAGE and mass spectrometry for obtaining a proteomic map for transgenic soybean seeds. The literature reports [12] that the number of protein spots present in the linear $\mathrm{pH}$ range from 4 to 7 was higher than the number of spots present in the linear range from 3 to 10 for transgenic soybean seeds. Therefore, for the range from 4 to 7 , a higher number of spots were selected when compared with the 3-10 range. As result, a total of 192 proteins from transgenic soybean seeds were identified, 179 of them identified within the $\mathrm{pH}$ range from 4 to 7 , and 13 of them identified within the 3-10 $\mathrm{pH}$ range. Regarding the $\mathrm{pH}$ range from 4 to $7,49 \%$ of the spots present in the gel were identified in the database showing good efficiency with a similar study involving soybean published in the literature [80]. Regarding their biological functions, 50\% were related to storage function, $18 \%$ related in growth/cell division process, $9 \%$ involved in metabolic/ energy process, $6 \%$ related to protein transport, $4 \%$ corresponding to proteins involved in the disease/defense category and $21 \%$ in the category of non-classified proteins.

The application of the 2-D PAGE technique in comparative proteomic studies can lead to some problems due to the intrinsic characteristics of the electrophoretic systems such as sample preparation strategies, the natural variations when considering biological systems, gel-to-gel variance, labor intensiveness and possible identification of several proteins from one spot $[67,81]$. In this sense, $2-\mathrm{DE}$ technologies need to be evaluated critically.

In a pioneering work, reference [66] evaluates some parameters that influence the comparisons of the protein map after different gel runs, establishing comparative image analysis after 2-D PAGE of transgenic and non-transgenic soybean seeds for identifying possible differences in protein expression. In that work, two $\mathrm{pH}$ ranges were used: 3-10 and 4-7. For improving accuracy, image treatments were made by the same analyst and concomitantly 
carried out for each pair of gels in the same electrophoretic run (4 pairs of gels with the optimized loaded mass) for avoiding possible variations between evaluations of the gel images.

In relation to detection and selection of the protein spots, the choice of the parameters of image analysis is extremely important. Differences between manual and automatic detection of the spots were obtained, showing the importance in editing the images to avoid erroneous interpretations not only in terms of the quantities of the detected spots, but also in terms of the intensities and/or volume of each protein detected.

The matching study is of utmost importance for those ones where the target is to find possible changes in protein expression as well as to establish the similarities in protein distribution in sets of gels. For gels obtained in the same run and within 3 to 10 and 4 to $7 \mathrm{pH}$ ranges, $163 \pm 37(79 \pm 4 \%$ match) and $287 \pm 28$ spots $(77 \pm 2 \%$ match) were respectively obtained from 4 pairs of gels (transgenic $x$ non-transgenic). However, when gels were obtained from different runs, even considering the same sample (transgenic seeds), high variation was detected in terms of matches $(39 \pm 6 \%$ and $58 \pm 13 \%$ for $3-10$ and $4-7 \mathrm{pH}$ ranges gels, respectively). Similar results for non-transgenic seeds were obtained $(40 \pm 10 \%$ and $62 \pm 18 \%$ for $3-10$ and 4-7 pH gel ranges, respectively). In this way, it is preferable to acquire the gels in the same run in order to produce high matches. The use of these procedures points out that elimination of gel-to-gel variation is mandatory in image analysis.

Proteins were considered as up or down regulated when the ratio between spot volume and/or intensity for non-transgenic and transgenic soybean seeds changed from $<0.55$ to $>1.8$ (ca. $90 \%$ variation). Thus, 3 and 7 spots from 3 to 10 and 4 to $7 \mathrm{pH}$ ranges were respectively highlighted and characterized by MALDI-QTOF MS. From this total, 8 proteins were identified as: glycinin G2/A2B1 precursor, glycinin G1 precursor, $\alpha$-subunit of $\beta$-conglycinin (03 spots), allergen Gly mBd $28 \mathrm{~K}$ (fragment), actin (fragment) and sucrose binding protein.

Then, it is easy to observe that well optimized conditions for acquiring images from 2D gels are an important tool in the identification of possible biomarkers for genetically modified organisms.

\section{Two-dimensional difference gel electrophoresis: 2-D DIGE}

A promising alternative for circumventing possible variations in the technique already described (2-D PAGE) is the two-dimensional difference gel electrophoresis (2-D DIGE). This technique, which is based on fluorescent cyanine dyes, allows comparisons between two exact quantitative proteomic samples, which are resolved on the same gel, minimizing the problems previously mentioned [82]. Moreover, there is the advantage of the high sensitivity of these dyes (ca. $1 \mathrm{fmol}$ of protein), which enables the detection of low abundance proteins when compared to other dyes used in the detection of protein spots, such as Coomassie Brilliant Blue (CBB) and silver staining [82]. Frequently, three samples are labeled in 2-D DIGE: two of them are experimental samples whereas the third one is composed of a mixture of equal amounts of all experimental samples (i.e., a pooled internal 
standard). This creates a standard for each protein during analysis. After 2D separation, different protein samples labeled can be visualized separately by exciting the different dyes at their specific excitation wavelengths. Therefore, from the images generated for each dye, the signals from labeled protein spots are determined and the normalized intensities or spot volumes for each spot from different dyes (Cy2, Cy3, Cy5) are compared in order to identify differentially expressed proteins between the samples [82-83].

Once this technique is finely developed for finding possible biomarkers, reference [79] applied the 2-D DIGE technique and mass spectrometry (ESI-QTOF MS/MS) to assess differences in proteomic profiles of transgenic and non-transgenic soybean seeds. Three biological replicates were analyzed. A regulation factor of 1.5 (50\% variation) was chosen as determined by the image analysis program and statistically significant differences in expression were determined ( $\mathrm{p} \leq 0.05$, according to the Student $t$ test). The program of image analysis uses the automatic detection of the spots, and does not require any manual editing, either in adding or in altering the area defining the spots, in contrast to other programs for 2-D PAGE image.

As a result, a total of four proteins were differentially expressed between transgenic and non-transgenic soybean seeds, where two were overexpressed, being more highly expressed in transgenic soybean, and two were underexpressed, being less expressed in transgenic soybean. Thus, these four spots were selected for identification by mass spectrometry. As results, the spots were identified as: Actin (fragment) (Glycine max), involved in various types of cell motility, widely expressed in all eukaryotic cells and binds to ATP and other proteins [84]; cytosolic glutamine synthetase (Cucumis melo) (Figure 1a), considered as a ligand enzyme, being highly expressed in many types of roots, binds ATP molecules and is responsible for the primary assimilation of ammonia in all living organisms, participates in nitrogen fixation [84]; Glycinin subunit G1 (Glycine max), responsible for the nutritional, physicochemical, and physiological characteristics of soybean seeds [85] and Glycine-rich RNA-binding protein (Glycine max) (Figure 1b), involved in cellular response to environmental and developmental conditions [84]. It is noteworthy that the actin protein was also detected by Brandão et al. [66] working with 2-D PAGE and image analysis, and with the same sample.

The results obtained in reference [79], comments about some differential proteins found, establishing a relationship between oxidative stress (ROS production) and genetic modification. In this way, spectrophotometric enzymatic assays demonstrate that soybean transgenic seeds (for glyphosate resistance) exhibited higher activities for APX, CAT and GR enzymes compared to non-transgenic. Considering these results, the authors concluded that the oxidative stressful condition in transgenic seeds resulted in an increase of $\mathrm{H}_{2} \mathrm{O}_{2}$, which is probably controlled by the action of APX and CAT and even GR. Related to SOD, reference [79] showed the results for SOD activity in nondenaturing polyacrylamide gel electrophoresis, and it was possible to observe eight SOD isoenzymes detected in both transgenic and nontransgenic soybean seeds, one as Mn-SOD, two as Fe-SOD and five as Cu/Zn-SOD. The authors commented that the reduction in SOD activity in transgenic seeds was much more a 
result of a reduction in the Fe-SOD isoenzymes activities. Finally, and as a conclusion, the genetic modification itself might have induced extra ROS generation.

Proteins involved in the RNA processing and alternative splicing, RNA transport, messenger RNA (mRNA) translation, mRNA stability, and mRNA silencing mechanisms have been shown to be required for normal plant development and the responses of plants to altered environments [86-87]. In our case, just the glycine-rich RNA-binding protein was differentially found after DIGE analysis, and this protein correlated to ROS production according to different articles [88, 89]. As already mentioned, the cytosolic glutamine synthetase is involved in nitrogen fixation. Oxidative stress can also control the expression of nitrogen-metabolism genes as recently demonstrated [90], demonstrating that cytosolic glutamine synthetase can be altered because of the oxidative stress observed in the transgenic soybean line [90].

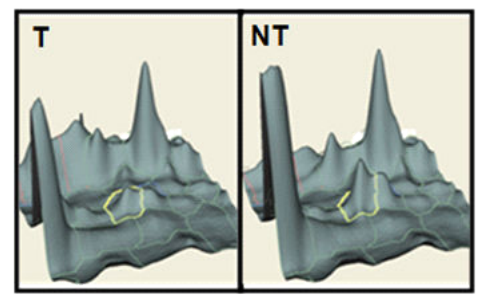

(a)

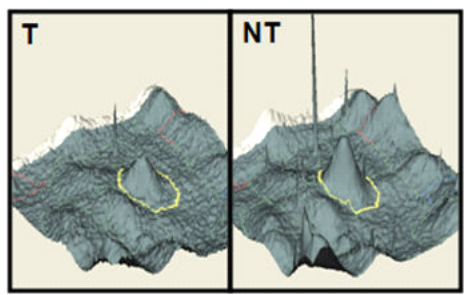

(b)

Figure 1. Examples of spots with expression variation among samples of transgenic (T) and non-transgenic (NT) soybean seeds: a - cytosolic glutamine synthetase (Cucumis melo) and b - Glycine-rich RNA-binding protein (Glycine max) [modified from reference 79].

\section{Metallomics studies involving HPLC coupled to ICP-MS}

In the last years, many soybean varieties have been genetically modified for adaptation to different geographical regions, to increase quality and productivity. Due to these genetic modifications, the proteins composition and profile can be affected, causing changes in the species proteome [91-92]. As previously described, the knowledge of the soybean genotype alone does not show enough information about the protein modifications due to environmental interactions. For better understanding of the consequences of a genetic manipulation, the elucidation of the protein map composition is necessary because it is directly related to the phenotype [93]. Since the proteome can be affected, it is assumed that the metallome can also be affected somehow by the genetic modification [94].

The metallome is defined as the entirety of metals and metalloid species, present in a cell or tissue type [95]. Deciphering the metallome provides information such as: (i) how an element is distributed among the cellular compartments; (ii) its coordination environment, in which the biomolecule is incorporated or by which bioligand it is complexed, and (iii) the 
concentration of the individual metal species present [96]. The majority of metals present in biological fluids and organs are linked to proteins, called metalloproteins. It is believed that every third protein require a metal cofactor, such as $\mathrm{Cu}, \mathrm{Fe}$ and $\mathrm{Zn}$, to develop their functions correctly [97]. The determination of an organism metallome involves separation techniques associated to microanalytic processes, such as mass spectrometry. These are the two key steps for general proteomics: separation and posterior identification of the proteins [80].

Metallomics studies were already performed in our group, being that one involving comparative metallomics of transgenic and non-transgenic soybean seeds [94], the first published in the literature. Soybean proteins were separated using two-dimensional polyacrylamide gel electrophoresis (2-D PAGE), tryptically digested, characterized using matrix assisted laser desorption ionization - quadrupole time of flight - mass spectrometry (MALDI-Q-TOFMS) and mapped using synchrotron X-ray fluorescence radiation (SR-XRF). The following metallic ions were found: $\mathrm{Ca}(\mathrm{II}), \mathrm{Cu}(\mathrm{II}), \mathrm{Fe}(\mathrm{II}), \mathrm{Mn}(\mathrm{II}), \mathrm{Ni}(\mathrm{II})$ and $\mathrm{Zn}(\mathrm{II})$, and the quantitative profile was acquired using atomic absorption spectrometry, showing changes in metal contents of transgenic and non-transgenic soybean seeds. Although promising results could be found in this study, the canonical analytical approaches for proteomics (such as 2-D PAGE) and metabolomics studies usually do not consider the existence of metal complexes with proteins and metabolites.

In this way, the use of high performance liquid chromatography (HPLC), an analytical technique used to separate a mixture in solution in its individual components, should be considered. Distinctly compared from 2-D PAGE, HPLC is based on different proteinsurface interactions [98]. The principal HPLC separation mechanisms used for bioinorganic studies include size exclusion chromatography (SEC), reversed-phase (RP) and ionexchange (IEX) chromatography, and because of the complex nature of the metalmolecule interaction, a combination of these mechanisms is often necessary to identify the elemental species correctly.

Together with HPLC, an element-specific detector must be used, and since the 80's, inductively coupled plasma mass spectrometry (ICP-MS) is being widely applied for studying elements at low concentrations. It is robust for multielementar determinations, allowing to reach extremely low detection limits and giving isotopic information for identification and quantification of the species, besides being easily coupled to classic separation techniques, such as HPLC, readily realized since the chromatographic flow $\left(0.5-1.0 \mathrm{~mL} \mathrm{~min}^{-1}\right)$ is compatible to common ICP-MS nebulizers [97,99].

The excitation source of this technique is argon inductively coupled plasma, which is used to form ions which are transferred to a high vacuum region through an interface containing small orifices. Ions are focalized using ionic lenses and directed to the mass spectrometer in order to be separated by $\mathrm{m} / \mathrm{z}$ ratio. The $\mathrm{m} / \mathrm{z}$ ratio analyzer generally used in ICP-MS is a quadrupole, ideal for quantitative analysis [100].

The elements detected using ICP-MS include metal coordination complexes with larger proteins and metallothioneins, as well as selenoproteins and metal/semi-metals linked to carbo- 
hydrates. A great amount of examples are found in the literature where ICP-MS is used to detect and quantify metallic ions bounded to biomolecules.

The attempts to avoid metal-ligand denaturation make the SEC mechanism the most used for metallomics studies [97]. It separates molecules according to their hydrodynamic volume, determined by their Stokes ratio. It results in the partial exclusion of analytes that pass through defined size pores due to their molecular sizes [101]. When the mobile phase passes through the column, those particles with small hydrodynamic volumes are transported through a larger path because they equilibrate in the pores more frequently than the ones with higher hydrodynamic volumes, resulting in separation. Elution volume is determined by the molecule size, directly related to their molecular weight, so this volume can be used to determine the molecular weight of an unknown compound. For carrying out that task, the relation between molecular weight and elution volume, obtained empirically by injecting standards with known molecular weight and measuring their elution volumes, must be known [102-103].

SEC is especially suitable for separation of element species presenting limited stability frequently found in protein-rich matrices. The main advantages of SEC are simplicity of application, tolerance to biological matrices, compatibility of mobile phases with specific demands of certain biological samples and the possibility of estimation of molecular weights of the compounds. It is widely used for protein separation, including soybean proteins and, although considered a low resolution method [104], it is often applied as the first separation method of fractions containing metallo-biomolecules of interest followed by another separation step with element-specific detection or MS identification. Its uses alone is very helpful to study the distribution of elements in different molecular weight fractions, and the coupling SEC-ICP-MS is being accepted as a hyphenated technique for speciation studies to evaluate the association of elements to compounds present in the sample. These studies are considered the initial point for a deeper evaluation of the nature of the species found.

In a work developed in our group [105], a comparison between elution profiles from transgenic and non-transgenic soybean seeds was carried out, using SEC coupled to high resolution ICP-MS. The elution profiles were similar between the samples, and the conclusions are in agreement to the ones discussed by reference [106]. It was found that areas of the most abundant peaks for $\mathrm{Cu}$ and Fe in transgenic soybean seeds were 3- and 2-fold higher, respectively, than those found in non-transgenic samples. This, summed up with total element analysis results in the same article, where the concentrations of $\mathrm{Cu}$ and Fe had statistically significant differences between transgenic and non-transgenic soybean seeds, could lead to the conclusion that $\mathrm{Cu}$ and $\mathrm{Fe}$ are associated with compounds more expressed in transgenic soybean seeds.

Reference [107] used different parts of the soybean plants to analyze Se elution profile using SEC-ICP-MS. The authors concluded that the bean had the most interesting profile, since it absorbed most of the Se from the shoots and presented a very intense peak for this element at higher molecular weight fraction. These data showed that the soybean plants convert selenite (used to enrich the plant) to high molecular weight species, which, according to the authors, can add nutritional value to the plant. Another work from the same group [108] 
used reversed phase coupled to ICP-MS to study the Se-Hg antagonism, and they found that in plants enriched with $\mathrm{Hg}$, more Se was assimilated, indicating a possible protective response mechanism to the $\mathrm{Hg}$.

As already commented, it is known that purity of peaks in SEC is poor, and even if a single species of a given element is present, matrix components may co-elute. They are invisible to the element specific detector, but if the goal is the identification of the organic specie linked to the element, they will be detected by the organic MS instrument. Also, matching the elution volume with a standard in this case is not definitive, due to the small number of theoretical plates found in SEC. For these reasons, SEC is usually followed by a second chromatographic separation ( $2^{\text {nd }}$ dimension) using an orthogonal separation mechanism, such as ion-exchange, reversed-phase or hydrophilic interaction chromatography, before the identification of the components.

Multidimensional liquid chromatography is an efficient tool and an alternative procedure for the classic methods based on unidimensional HPLC. The multidimensional chromatography can be carried out online or off-line. In the off-line mode, fractions eluted from the $1^{\text {st }}$ dimension are collected manually or using a fraction collector, and then are re-injected in the second chromatographic column. Online techniques are automated using a selector valve, which can enhance reliability and sample processing. The limitation here is that the mobile phases used for both dimensions must be compatible [109].

The selectivity in a multidimensional system can be enhanced only if the chromatographic dimensions are based in different separation mechanisms. The second dimension must not decrease the resolution obtained using the previous one. For the separation mechanisms to be different, the columns must have different stationary phases, allowing the less efficient separation attained in the first dimension to be improved in the second [110].

In the case of multidimensional liquid chromatography [103,111] coupled to ICP-MS, fractions isolated mainly using SEC, can be fractionated again using an independent separation mechanism to provide more detailed results, and also to attain metal species pure enough to be characterized using molecular mass spectrometry.

Many stationary phases can be used for a second chromatographic dimension. Among then, reversed phase (RP) [111], the most popular liquid chromatography separation mechanism, should be highlighted. It has great efficiency and is able to separate a great range of compounds with different polarities. The separation is obtained through partition of the analyte between a non-polar stationary phase and a polar mobile phase.

Ion exchange chromatography [112] (IEX) can also be used to separate biomolecules based in charge differences. It can be considered a highly selective technique, able to separate, for example, proteins differing in only one charged group. It is a widely used technique in bioseparations, since peptides, proteins, nucleic acids and related biopolymers have ionizable chemical domains, making them susceptible to enhancement or diminishment of their charges as a function of $\mathrm{pH}$ and ionic strength changes. It can be used to separate large biomolecules, with more than $60 \mathrm{kDa}$. 
Finally, polar compounds can beefficiently separated using polar/hydrophilicstationary phases using normal phase aqueous chromatography (aqNPC), also called hydrophilicinteraction chromatography (HILIC) [113]. Here, retention timestend to belongerashighasis thehydrophobicity of thesolutes, indicating potential forsmallmetalliccomplexesseparation.

Concerning multidimensional chromatographic separations and soybeans, a recent work from reference [107] used IEX as second dimension for the separation of proteins from selenium-enriched soybean. Here, the target was only Se, and the 26 fractions collected from the second dimension were pure enough to allow the identification of a considerable number of proteins in the soybean databank.

In our group [114], IEX was also used as second dimension, generating a number of different fractions for both transgenic and non-transgenic soybean seeds used in that research. Taking as an example cobalt, the SEC separation (Figure 2a) provided 3 peaks, divided into F1, F2, and F3. When F3 is separated again using IEX (Figure 2b), the wide peak found using SEC was separated into two narrow peaks, showing that the separation resolution increased.
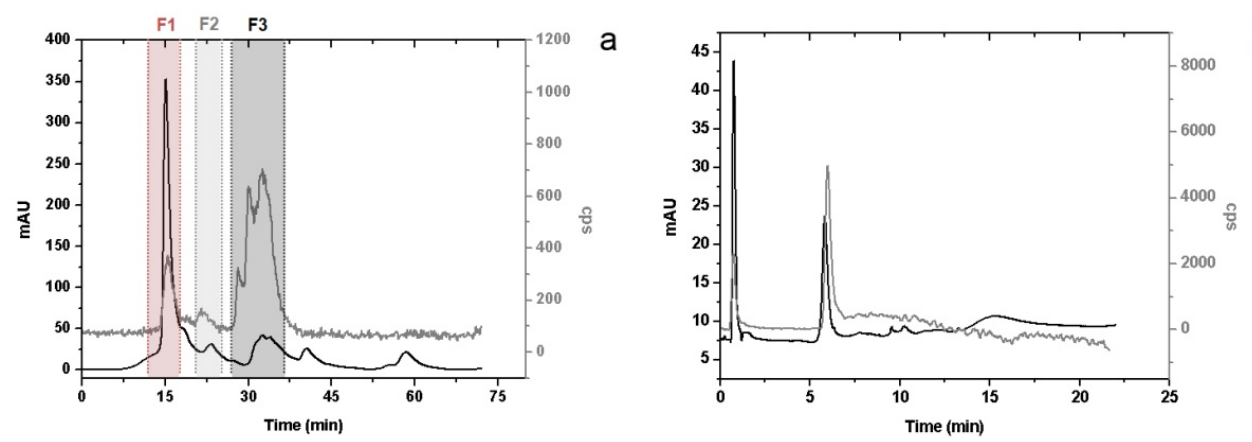

Figure 2. Chromatograms for UV absorption at $280 \mathrm{~nm}(-)$ and Co signal in the ICP-MS (-) for (a) SEC, separated in three fractions: F1, F2 and F3; and (b) IEX separation of F3 using transgenic soybean seeds [modified from supplementary material of reference 114].

Nowadays, mass spectrometry associated to bioinformatics has become essential in studies involving proteins, not only due to their sensitivity, but also to the total of information that can be obtained [69]. Electrospray ionization (ESI) is the most used technique for protein identification, allowing the formation of ions in the gas phase using a soft ionization process, making possible the analysis of non-volatile and thermolabile compounds [115]. As a consequence, ESI facilitated the analysis of large biomolecules, as well as drugs and their metabolites.

To improve metallomics information concerning transgenic and non-transgenic soybean seeds, ourgroup [114] used themultidimensionalchromatographystrategy, aspointed outpreviouslyin thistext. Totalamounts ofFeand Cuwerealready found tobehigherintransgenicsoybeans, and in anattempttolink thesemetalstoproteins, anESI-MS/MSanalysiswascarried out. Asresults, more 
than 20 proteins wereidentified, encompassing 4 differentfunctional categories. Among them, $\beta$ conglycinin, a protein previously associated to metals, was identified in three fractions, and one metalloproteinthatbindsFe,lypoxigenase1, wasfoundinahighmolecularweightfraction, theonly fraction whereanFepeak wasseparated.

\section{Future trends}

Currently, the comparative studies concerning alterations in proteins, metalloproteins, metals and enzymes have demonstrated significant differences among transgenic and nontransgenic soybean. These differences have indicated that these genetic modifications provide not only tolerance to herbicide but also cause many changes in the whole metabolism of the transgenic plants.

Carefully taking into account all the results presented, it is possible to raise the following question: what are the future trends in comparative studies involving transgenic and nontransgenic soybean? Since the whole metabolism of transgenic soybean plants seems to be different to the non-transgenic one, this is a promising research area, and too much work is still needed. Much more information is still ahead of us for a better comprehension of the specific aspects of the transgenic soybean plant metabolism. In this way, investigations into techniques and novel approaches, quantitative proteomics, imaging and mapping of elemental distribution, tracer experiments employing stable isotopes and also in natural variation in the isotopic composition of the elements may possibly be the future trends in this topic. This will contribute to elucidation and expansion of our knowledge about transgenic soybean.

Since the proper functioning of life depends on the elements in a variety of processes, the understanding of molecular mechanisms of the elements and information on its chemical forms present in a living organism are very important. In this context, studies about identification and/or quantification of one or more chemical species of elements in transgenic and non-transgenic soybean samples are able to generate valuable information about their metabolisms. Therefore, it would be useful if more efforts were devoted to this topic. A novel technique that has an unexplored potential for speciation analysis is travelling wave ion mobility spectrometry coupled to mass spectrometry (TWIMS-MS) [116]. The use of this technique in speciation analysis of metals associated with biomolecules should increase due to its capability of differentiation of ions by shape and size, besides mass and charge. Until now, the studies employing ion mobility are concentrated in proof-of-the-concept using isolated species commercially available and its application to complex matrices certainly will be a big challenge, but very helpful to elucidate many questions.

The main objective of quantitative proteomics is to quantify protein expression alterations in response to a variety of changes, and, nowadays, one of the most challenging and emerging area of proteomics involves the developments of accurate quantitative methods for proteins. The quantitative proteomics is divided in absolute and relative subjects. In the absolute quantification, changes in protein expression are determined in exact amount or concentra- 
tion of each protein present. The relative one determines the up- or down-regulation of a protein relative to the control sample, and the results are presented as 'fold' increases or decreases. The 2-D DIGE is an example of relative quantification technique that is applied to intact proteins and the differential expression determination is based on fluorescence as commented earlier in this chapter. Taking into account the soybean comparative studies the application of quantitative proteomics by 2-D DIGE or by other technique could continue establishing the differences in protein expressions accurately [117].

According to the results presented earlier, some elements are present at higher concentrations in transgenic soybean seeds than in non-transgenic ones $[66,94,105]$. The transgenic seed seems to haveability totakeuphigheramountsof somemetalsfrom thesoiland thisisasignthat the processes involved in intake, transport and storage of essential and toxic metals and metalloids probably are suffering changes due to genetic modification. Various new queries take place with this information, suchas:Theothertransgenicplantparts(roots, stemsandleaves), arealsotakingup, transporting and storinghigheramounts of thesemetals? Other plant partstry toeliminatesomeexcess of these metals? Are these higher amounts really an excess for a transgenic plant or not? Are there differences in the distributions of these metals among transgenic and non-transgenic soybean? A potential tool for obtaining a better insight in these processes can be to use tracer experiments employing stable isotopes. In the last few years the use of stableisotopes and their isotope ratio measurementshavegained importancefor tracerexperimentsinbiological and medical research [118]. In thesestudies stableisotopic tracers with an isotopic composition sufficiently different from the corresponding natural oneis added to thestudied system and changesin the selected isotoperatio monitored. The absorption or bioavailability of an element can be determined with this approach as well as information about element redistribution over various compartments of an organism [118-119]. According to our knowledge, no tracer study for essential or toxic metals evaluating transgenic and non-transgenic soybean is found in the literature and therefore there is a great amountof work toperforminthischallenging area.

LA-ICP-MS offers in situ analysis of solid samples with respect to metals and nonmetals at trace concentration level mostly without sample preparation and without charging effects during the measurements. This technique can also be applied to the imaging of soft tissues such as plant leaves with relatively high spatial resolution and good sensitivity [120] and therefore, some investigations involving metals distribution by LA-ICP-MS in transgenic and non-transgenic soybean would also be a future trend.

Another challenging issue that can provide evidences supporting the hypothesis that genetic modification is affecting the metabolism of soybean plants involves the investigation of natural variation in the isotopic composition of the elements. Even though isotopic abundances are assumed to be almost constant in nature, small isotopic or mass fractionation effects occur in both natural and industrial processes [118]. Since the isotopes present the same number of electrons, they show basically the same chemical behavior. However, there is a small discrepancy in their physicochemical behavior due to the mass difference, which may leave isotopes of the same element to take part with slightly different efficiencies in physical processes or (bio)chemical reactions, and, consequently, to result in variations in the isotopic composition [118-119]. These differences in efficiency are associated to a minor distinction in 
equilibrium for each different isotopic molecule - thermodynamic effect or in the rate with which the isotopes participate in a process or reaction - kinetic effect. Lighter elements, such as $\mathrm{H}, \mathrm{C}, \mathrm{N}, \mathrm{O}$ and $\mathrm{S}$ suffer more pronounced isotopic variations because of the high relative mass difference between their isotopes. Nevertheless, heavier elements are subject to isotope fractionation, even though the change is minor [121].

As relative abundances cannot be measured directly, these studies are based on measuring the isotope ratio of an element because it is experimental accessible. The isotope ratio measured in a particular sample $\left(R_{x}\right)$ is compared to the corresponding one in another sample, frequently a reference sample $\left(R_{R F}\right)$ [118]. The differences found are frequently very small and thus high reproducibility/repeatability is required. Thus, the ICP-MS technique is becoming the more advantageous choice for most applications employing isotope ratios, mainly considering the recent instrumental developments. As the elements are subject to isotope fractionation in nature, the genetic modification could also provoke or intensify this effect.

In view of that comment here, it is easy to rationalize that many aspects can be explored when focusing on studies related to transgenic soybean.

\section{Conclusion}

The initial hypothesis formulated that the genetic modification itself is stressing the soybean, is apparently right, once the plant is searching a new equilibrium as living organism. The results presented in this chapter demonstrate that not only is the proteomic map changed with some proteins increasing and others decreasing, but also chromatographic separations are altered when transgenic and non-transgenic soybeans are compared. Examples are activities of some enzymes (as CAT, SOD, GPx, among others) involved in neutralization of ROS, as well as the possible capacity in taking metals from the soil (mainly for Fe and $\mathrm{Cu}$ ). Because of these modifications that occur when both transgenic and non-transgenic organisms are compared, the theme of genetic modification could be even better explained with some alternative strategies, such as quantitative proteomics, image analysis, tracer experiments with stable isotopes, and other possibilities.

Finally, in our point of view, one of the key points for the success of studies involving transgenic organisms is not only to involve good technology, but also a transdisciplinary view, involving different areas of expertise. With this strategy, it will be easier to understand this area of investigation, making possible the demystification of the genetic modification that have occurred, and allowing answers for some questions that still remain unknown.

\section{Nomenclature and acronyms}

2-D-HPLC Two-Dimensional High Performance Liquid Chromatography

2-D PAGE Two-Dimensional Gel Electrophoresis 
2-D DIGE Two-Dimensional Difference Gel Electrophoresis

ICP-MS Inductively Coupled Plasma Mass Spectrometry

HR-SF-ICP-MSHighResolutionSectorFieldInductivelyCoupledPlasmaMassSpectrometry

LA-ICP-MS Laser Ablation Inductively Coupled Plasma Mass Spectrometry

MALDI-QTOF-MS Matrix-Assisted Laser Desorption Ionisation Quadrupole-Time-of-Flight Mass Spectrometry

ESI-LC-MS-MS ElectroSpray Ionization Liquid Chromatography Mass Spectrometry-Mass Spectrometry

2-D-HPLC-ICP-MS Two-Dimensional High Performance Liquid Chromatography Inductively Coupled Plasma Mass Spectrometry

SDS-PAGE Sodium Dodecyl Sulfate Polyacrylamide Gel Electrophoresis

ESI-QTOFMS-MSElectroSpray Ionization-Time-of-FlightMassSpectrometry-MassSpectrometry

SEC-ICP-MSSizeExclusionChromatography-InductivelyCoupledPlasmaMassSpectrometry

\section{Acknowledgements}

The authors are grateful to the Fundação de Amparo a Pesquisa do Estado de São Paulo (FAPESP, São Paulo, Brazil), Conselho Nacional de Desenvolvimento Científico e Tecnológico (CNPq, Brasília, Brazil), and Coordenação de Aperfeiçoamento de Pessoal de Nível Superior (CAPES, Brasília, Brazil), for financial support.

\section{Author details}

Marco Aurélio Zezzi Arruda ${ }^{1}$, Ricardo Antunes Azevedo ${ }^{2}$, Herbert de Sousa Barbosa ${ }^{1}$, Lidiane Raquel Verola Mataveli ${ }^{1}$, Silvana Ruella Oliveira ${ }^{1}$,

Sandra Cristina Capaldi Arruda ${ }^{2}$ and Priscila Lupino Gratão ${ }^{3}$

1 Institute of Chemistry, National Institute of Science and Technology for Bioanalytics and Department of Analytical Chemistry, University of Campinas, Campinas, Brazil

2 Department of Genetics, Laboratory of Genetics Biochemistry of Plants, University of São Paulo, ESALQ, Piracicaba, Brazil

3 Department of Applied Biology to Agricultural, Universidade Estadual Paulista, FCAV, Jaboticabal, Brazil 


\section{References}

[1] Sharma S, Kaur M, Goysil R, Gil BS. Physical Characteristics and Nutritional Composition of Some New Soybean (Glycine max (L.) Merrill) genotypes. Journal of Food Science and Technology 2011; DOI:10.1007/s13197-011-0517-7.

[2] The American Soybean Association. SoyStats. http://www.soystats.com (accessed 3 May 2012).

[3] Rural Centro. http://www.ruralcentro.com.br/noticias/53562/usda-reduz-producaode-soja-da-safra-201112-para-2515-milhoes (accessed 21 March 2012).

[4] Cavusoglu K, Yapar K, Oruc E, Yalcin E. Protective Effect of Ginkgo Biloba L. Leaf Extract Against Glyphosate Toxicity in Swiss Albino Mice. Journal of Medicinal Food 2011;14(10) 1263-1272.

[5] Windels P., Tavernies I., Depicker A., Van Bockstaele E., De Loose M. Characterisation of the Roundup Ready Soybean Insert. European Food Research and Technology 2001;213(2) 107-112.

[6] Monsanto do Brasil. http://www.monsanto.com.br (acessed May 15 2012).

[7] Saz JM, Marina ML. High Performance Liquid Chromatography and Capillary Electrophoresis in the Analysis of Soybean Proteins and Peptides in Foodstuffs. Journal of Separation Science 2007;30(4) 431-451.

[8] Scandalios JG. Oxidative Stress: Molecular Perception and Transduction of Signals Triggering Antioxidant Gene defenses. Brazilian Journal of Medical and Biological Research 2005;38(7) 995-1014.

[9] Scandalios J.G., Guan L., Polidoros A.N. Catalases in Plants:Gene Structure, Properties, Regulation, and Expression. In: Scandalios J.G. (ed.) Oxidative Stress and the Molecular Biology of Antioxidant Defenses. New York: Cold Spring Harbor Laboratory Press Plainview; 1997. p343-406.

[10] Fridovich I. Superoxide Radical and Superoxide Dismutases. Annual Review of Biochemistry 1995;64 87-112.

[11] Hippeli S, Heiser I, Elstner EF. Activated Oxygen and Free Oxygen Radicals in Pathology:New Insights and Analogies Between Animals and Plants. Plant Physiology Biochemistry 1999;37(3) 167-178.

[12] Levine A, Tenhaken R, Dixon R, Lamb C. H2O2 from the Oxidative Burst Orchestrates the Plant Hypersensitive Disease Resistance Response. Cell 1994;79(4) 583-593.

[13] Dat J, Vandenabeele S, Vranová E, Van Montagu M, Inzé D, Van Breusegem F. Dual Action of the Active Oxygen Species During Plant Stress Responses. Cellular and Molecular Life Sciences 2000;57(5) 779-795. 
[14] Foyer, CH, Shigeru S. Understanding Oxidative Stress and Antioxidant Functions to Enhance Photosynthesis. Plant Physiology 2011;155(1) 93-100.

[15] Foyer, CH, Noctor G. Redox Homeostasis and Antioxidant Signaling: A Metabolic Interface between Stress Perception and Physiological Responses. The Plant Cell 2005;17(7) 1866-1875

[16] Gratão PL, Polle A, Lea PJ, Azevedo RA. Making the Life of Heavy Metal-Stressed Plants a Little Easier. Functional Plant Biology 2005;32(6) 481-494.

[17] Jones DP. Redefining Oxidative Stress. Antioxidant Redox Signaling 2006;8(9-10) 1865-1879.

[18] Foyer CH, Noctor G. Oxidant and Antioxidant Signaling in Plants: a Re-Evaluation of the Concept of Oxidative Stress in a Physiological Context. Plant Cell Environment 2005;28(8) 1056-1071.

[19] Foyer CH, Noctor G. Oxygen Processing in Photosynthesis: Regulation and Signaling. New phytologist 2000;146(3) 359-388.

[20] Rizhsky L, Hallak-Herr E, Van Breusegem F, Rachmilevitch S, Barr JE, Rodermel S, Inzé D, Mitler R. Double Antisense Plants Lacking Ascorbate Peroxidase and Catalase are Less Sensitive to Oxidative Stress than Single Antisense Plants Lacking Ascorbate Peroxidase or Catalase. Plant Journal 2002;32(3) 329-342.

[21] Moller IM. Plant Mitochondria and Oxidative Stress: Electron Transport, NADPH Turnover, and Metabolism of Reactive Oxygen Species. Annual Review of Plant Physiology and Plant Molecular Biology 2001;52 561-591.

[22] Medici LO, Azevedo RA, Smith RJ, Lea PJ. The Influence of Nitrogen Supply on Antioxidant Enzymes in Plant Roots. Functional Plant Biology 2004;31(1) 1-9.

[23] Bechtold U, Murphy DJ, Mullineaux PM. Arabidopsis Peptide Methionine Sulfoxide Reductase 2 Prevents Cellular Oxidative Damage in Long Nights. The Plant Cell 200;16(4) 908-919.

[24] Wojtaszek P. Oxidative Burst: an Early Plant Response to Pathogen Infection. Biochemical Journal 1997;322(3) 681-692.

[25] Yu W, Zhang R, Runzhi L, Sandui G. Isolation and Characterization of GlyphosateRegulated Genes in Soybean Seedlings. Plant Science 2007;172(3) 497-504.

[26] Moldes CA, Médici LO, Abrahão OS, Tsai SM, Azevedo RA. Biochemical Responses of Glyphosate Resistant and Susceptible Soybean Plants Exposed to Glyphosate. Acta Physiologiae Plantarum 2008;30(4) 469-479.

[27] Knörzer O, Burner J, Boger P. Alterations in the Antioxidative System of SuspensionCultured Soybean Cells (Glycine Max) Induced by Oxidative Stress. Physiologia Plantarum 2008;97(2) 388-396. 
[28] Gill SS, Nafees AK, Narendra T. Differential Cadmium Stress Tolerance in Five Indian Mustard (Brassica Juncea L.) Cultivars. An evaluation of the role of antioxidant machinery. Plant Signaling and Behavior 2011;6(2) 293-300.

[29] Mittler R, Blumwald E. Genetic Engineering for Modern Agriculture: Challenges and Perspectives. Annual Review in Plant Biology. 2010;61 443-462

[30] Ghelfi A, Gaziola SA, Cia MC, Chabregas SM, Falco MC, Kuser-Falcão PR, Azevedo RA. Cloning, Expression, Molecular Modeling and Docking Analysis of Glutathione Transferase from Saccharum Officinarum. Annals of Applied Biology 2011;159(2) 267-280.

[31] Delaunay A, Pflieger D, Barrault MB, Vinh J, Toledano MB. A Thiol Peroxidase is an H2O2 Receptor and Redox-Transducer in Gene Activation. Cell 2002;111(4) 471-481.

[32] Arruda MAZ., Azevedo RA. Metallomics and Chemical Speciation: Towards a Better Understanding of Metal-Induced Stress in Plants. Annals of Applied Biology 2009;155(3) 301-307.

[33] Apel K, Hirt H. Reactive Oxygen Species: Metabolism, Oxidative Stress and Signal Transduction. Annual Review on Plant Biology 2004;55 373-399.

[34] Galant A, Koester RP, Ainsworth EA, Hicks LM. From climate change to molecular response: redox proteomics of ozone-induced responses in soybean. New Phytologist 2012;194(1) 220-229.

[35] Zhao T, Wang JL, Wang Y, Cao Y. Effects Of Antioxidant Enzymes of Ascorbate-Glutathione Cycle in Soybean (Glycine Max) Leaves Exposed to Ozone. Advanced Research on Industry, Information Systems and Material Engineering, pts 1-7 Advanced Materials Research 2011;204-210(1-7) 672-677.

[36] Gillespie KM, Rogers A, Ainsworth EA. Growth at Elevated Ozone or Elevated Carbon Dioxide Concentration Alters Antioxidant Capacity and Response to Acute Oxidative Stress in Soybean (Glycine Max). Journal of Experimental Botany 2011;62(8) 2667-2678.

[37] Singh E, Tiwari S, Agrawal M. Variability in Antioxidant and Metabolite Levels, Growth and Yield of Two Soybean Varieties: an Assessment of Anticipated Yield Losses under Projected Elevation of Ozone. Agriculturall Ecosystems \& Environment 2010;135(3) 168-177.

[38] Masoumi H, Darvish F, Daneshian J, Normohammadi G, Habibi D. Effects of Water Deficit Stress on Seed Yield and Antioxidants Content in Soybean (Glycine Max L.) Cultivars. African Journal of Agricultural Research 2011;6(5) 1209-1218.

[39] Masoumi H, Darvish F, Daneshian J, Nourmohammadi G, Habibi D. Chemical and Biochemical Responses of Soybean (Glycine Max L.) Cultivars to Water Deficit Stress. Australian Journal of Crop Science 2011;5(5) 544-553. 
[40] Dogan M. Antioxidative and Proline Potentials as a Protective Mechanism in Soybean Plants under Salinity Stress. African Journal of Biotechnology. 2011;10(32) 5972-5977.

[41] Moussa HR. Low Dose of Gamma Irradiation Enhanced Drought Tolerance in Soybean. Bulgarian Journal of Agricultural Science 2011;17(1) 63-72.

[42] Kocsy G, Laurie R, Szalai G, Szilagyi V, Simon-Sarkadi L, Galiba G, de Ronde JA. Genetic Manipulation of Proline Levels Affects Antioxidants in Soybean Subjected to Simultaneous Drought and Heat Stresses. Physiologia Plantarum 2005;124(2) 227-235.

[43] Yi H, Ravilious GE, Galant A, Krishnan HB, Jez JM. From Sulfur to Homoglutathione: Thiol Metabolism in Soybean. Amino Acids 2010;39(4) 963-978.

[44] Kim WS, Chronis D, Juergens M, Schroeder AC, Hyun SW, Jez JM, Krishnan HB. Transgenic Soybean Plants Overexpressing O-Acetylserine Sulfhydrylase Accumulate Enhanced Levels of Cysteine and Bowman-Birk Protease Inhibitor in Seeds. Planta $2012 ; 235(1)$ 13-23.

[45] Kumar V, Rani A, Dixit AK, Bhatnagar D, Chauhan GS. Relative Changes in Tocopherols, Isoflavones, Total Phenolic Content, and Antioxidative Activity in Soybean Seeds at Different Reproductive Stages. Journal of Agricultural and Food Chemistry 2009;57(7) 2705-2710.

[46] Pawlak S, Firych A, Rymer K, Deckert J. Cu,Zn-Superoxide Dismutase is Differently Regulated by Cadmium and Lead in Roots of Soybean Seedlings. Acta Physiologiae Plantarum 2009;31(4) 741-747.

[47] Melo LCA, Alleoni LRF, Carvalho G, Azevedo RA. Cadmium- and Barium-Toxicity Effects on Growth and Antioxidant Capacity of Soybean (Glycine Max L.) Plants, Grown in Two Soil Types with Different Physicochemical Properties. Journal of Plant Nutrition and Soil Science 2011;174(5) 847-859.

[48] Liu TT, Wu P, Wang LH, Zhou Q. Response of Soybean Seed Germination to Cadmium and Acid Rain. Biological Trace Element Research 2011;144(1-3) 1186-1196.

[49] Ershova AN, Popova NV, Berdnikova OS. Production of Reactive Oxygen Species and Antioxidant Enzymes of Pea and Soybean Plants under Hypoxia and High CO2 Concentration in Medium. Russian Journal of Plant Physiology 2011;58(6) 982-990.

[50] Shamsi IH, Wei K, Zhang GP, Jilani GH, Hassan MJ. Interactive Effects of Cadmium and Aluminum on Growth and Antioxidative Enzymes in Soybean. Biologia Plantarum 2008;52(1) 165-169.

[51] Sousa NR, Ramos MA, Marques APGC, Castro PML. The Effect of Ectomycorrhizal Fungi Forming Symbiosis with Pinus Pinaster Seedlings Exposed to Cadmium. Science of the Total Environment 2012;414 63-67. 
[52] Bressano M, Curetti M, Giachero L, Gil SV,Cabello M, March G, Ducasse DA, Luna CM. Mycorrhizal Fungi Symbiosis as a Strategy against Oxidative Stress in Soybean Plants. Journal of Plant Physiology 2010;167(18) 1622-1626.

[53] Ghorbanli M, Ebrahimzadeh H, Sharifi M. Effects of Nacl and Mycorrhizal Fungi on Antioxidative Enzymes in Soybean. Biologia Plantarum 2004;48(4) 575-581.

[54] Sugiyama M, Ae N, Arao T. Role of Roots in Differences in Seed Cadmium Concentration among Soybean Cultivars - Proof by Grafting Experiment. Plant Soil 2007;295(1-2) 1-11.

[55] Fields S. Proteomics in Genomeland. Science, 2001;291(5507) 1221-1224.

[56] Kersten B, Bürkle L, Kuhn EJ, Giavalisco P, Konthur Z, Lucking A, Walter G, Eickhoff H, Schneider U. Large-Scale Plant Proteomics. Plant Molecular Biology 2002;48 133-141.

[57] Job D, Haynes PA, Zivy M. Plant Proteomics. Proteomics 2011;11(9) 1557-1558.

[58] Wang Y, Kim SG, Kim ST, Agrawal GK, Rakwal R, Kang KY. Biotic Stress-Responsive Rice Proteome: an Overview. Journal of Plant Biology 2011;54(4) 219-226.

[59] Hossain Z, Nouri MZ, Komatsu S. Plant Cell Organelle Proteomics in Response to Abiotic Stress. Journal of Proteome Research 2012;11(1) 37-48.

[60] Komatsu S, Konishi H, Hashimoto M. The Proteomics of Plant Cell Membranes. Journal of Experimental Botany 2007;58(1) 103-112.

[61] Ito J, Batth TS, Petzold CJ, Redding-Johanson AM, Mukhopadhyay A, Verboom R, Meyer EH, Millar AH, Heazlewood JL. Analysis of the Arabidopsis Cytosolic Proteome Highlights Subcellular Partitioning of Central Plant Metabolism. Journal of Proteome Research 2011;10(4) 1571-1582.

[62] Cortleven A, Noben JP, Valcke R. Analysis of the Photosynthetic Apparatus in Transgenic Tobacco Plants with Altered Endogenous Cytokinin Content: A Proteomic Study. Proteome Science 2011;9(33) 1-14.

[63] Satoh R, Nakamura R, Komatsu A, Oshima M, Teshima R. Proteomic Analysis of Known and Candidate Rice Allergens between Non-Transgenic and Transgenic Plants. Regulatory Toxicology and Pharmacology 2011;59(3) 437-444.

[64] Uzogara SG. The Impact of Genetic Modification of Human Foods in the 21st Century: a Review. Biotechnology Advances 2000;18(3) 179-206.

[65] Kim Y, Choi SJ, Lee H, Moon TW. Quantitation of CP4 5-Enolpyruvylshikimate-3Phosphate Synthase in Soybean by Two-Dimensional Gel Electrophoresis. Journal of Microbiology and Biotechnology 2006;16(1) 25-31.

[66] Brandão AR, Barbosa HS, Arruda MAZ. Image Analysis of Two-Dimensional Gel Electrophoresis for Comparative Proteomics of Transgenic and Non-Transgenic Soybean Seeds. Journal of Proteomics 2010;73(8) 1433-1440. 
[67] Rabilloud T, Lelong C. Two-Dimensional Gel Electrophoresis in Proteomics: a Tutorial. Journal of Proteomics 2011;74(10) 1829-1841.

[68] Garcia JS, Souza GHMF, Eberlin MN, Arruda MAZ. Evaluation of Metal-Ion Stress in Sunflower (Helianthus Annus L.) Leaves through Proteomic Changes. Metallomics 2009;1(1) 107-113.

[69] Domon B., Aebersold R. Mass Spectrometry and Protein Analysis. Science 2006;312(5771) 212-217.

[70] Aebersold R, Mann M. Mass Spectrometry-Based Proteomics. Nature 2003;422(6928) 198-207.

[71] Sussulini A, Garcia JS, Mesko MF, Moraes DP, Flores EMM, Perez CA, Arruda MAZ. Evaluation of Soybean Seed Protein Extraction Focusing on Metalloprotein Analysis. Microchimica Acta 2007;158(1-2) 173-180.

[72] Arruda SCC, Barbosa HS, Azevedo RA, Arruda MAZ. Two-Dimensional Difference Gel Electrophoresis Applied for Analytical Proteomics: Fundamentals and Applications to the Study of Plant Proteomics. Analyst 2011;136(20) 4119-4126.

[73] Natarajan SS. Natural variability in abundance of prevalent soybean proteins. Regulatory Toxicology and Pharmacology 2010;58(3) 26-29.

[74] Cheng L, Gao X, Li S, Shi M, Javeed H, Jing X, Yang G, He G. Proteomic Analysis of Soybean [Glycine Max (L.) Meer.] Seeds During Inhibition at Chilling Temperature. Molecular Breeding 2010;26(1) 1-17.

[75] Toorchi M, Yukawa K, Nouri MZ, Komatsu S. Proteomics Approach for Identifying Osmotic-Stress-Related Proteins in Soybean Roots. Peptides 2009;30(12) 2108-2117.

[76] El-shemy HA, Khalafalla MM, Fujita K, Ishimoto M. Improvement of Protein Quality in Transgenic Soybean Plants. Biologia Platarum 2007;51(2) 277-284.

[77] Ocana MF, Fraser PD, Patel RKP, Halket JM, Bramley PM. Mass Spectrometric Detection of CP4 EPSPS in Genetically Modified Soya and Maize. Rapid Communication in Mass Spectrometry 2007;21(3) 319-328.

[78] Wittmann-Liebold B, Graack HR, Pohl T. Two-Dimensional Gel Electrophoresis as Tool for Proteomics Studies in Combination with Protein Identification by Mass Spectrometry. Proteomics 2006;6(17) 4688-4703.

[79] Barbosa HS, Arruda SCC, Azevedo RA, Arruda MAZ. New Insights on Proteomics of Transgenic Soybean Seeds: Evaluation of Differential Expressions of Enzymes and Proteins. Analytical and Bioanalytical Chemistry 2012;402(1) 299-314.

[80] Xu C, Garrett WM, Sullivan J, Caperna T, Natarajan SS. Separation and Identification of Soybean Leaf Proteins by Two-Dimensional Gel Electrophoresis and Mass Spectrometry. Phytochemistry 2006;67(22) 2431-2440. 
[81] Rabilloud T, Chevallet M, Luche S, Lelong C. Two-Dimensional Gel Electrophoresis in Proteomics: Past, Present and Future. Journal of Proteomics 2010;73(11) 2064-2077.

[82] Timms JF, Cramer R. Difference Gel Electrophoresis. Proteomics, 2008;8(23-24) 4886-4897.

[83] Marouga R, David S, Hawkins E. The Development of the DIGE System: 2D Fluorescence Difference Gel Analysis Technology. Analytical and Bioanalytical Chemistry 2005;382(3) 669-678.

[84] Wang W, Vinocur B, Altman A. Plant Responses to Drought, Salinity and Extreme Temperatures: Towards Genetic Engineering for Stress Tolerance. Planta 2003;218(1) 1-14.

[85] Thanh VH, Shibasaki K. Major Proteins of Soybean Seeds. Subunit Structure of BConglycinin. Journal of Agricutural and Food Chemistry 1978;26(3) 692-695.

[86] Cheng Y, Chen X. Posttranscriptional Control of Plant Development. Current Opinion in Plant Biology 2004;7(1) 20-25.

[87] Wang QL, Li ZH. The Functions of Micrornas in Plants. Frontiers in Bioscience 2007;12 3975-3982.

[88] Schmidt F, Marnef A, Cheung MK, Wilson I, Hancock J, Staiger D, Ladomery M. A Proteomic Analysis of Oligo(Dt)-Bound Mrnp Containing Oxidative Stress-Induced Arabidopsis Thaliana RNA-Binding Proteins ATGRP7 and ATGRP8. Molecular Biology Reports 2010;37(2) 839-845.

[89] Kim YO, Pan S, Jung CH, Kang H. A Zinc Finger-Containing Glycine-Rich RNABinding Protein, Atrz-1a, has a Negative Impact on Seed Germination and Seedling Growth of Arabidopsis Thaliana under Salt or Drought Stress Conditions. Plant and Cell Physiology 2007;48(8)1170-1181.

[90] Pageau K, Reisdorf-Cren M, Morot-Gaudry JF, Masclaux-Daubresse C. The Two Senescence-Related Markers, GS1 (Cytosolic Glutamine Synthetase) and GDH (Glutamate Dehydrogenase), Involved in Nitrogen Mobilization, are Differentially Regulated during Pathogen Attack and by Stress Hormones and Reactive Oxygen Species in Nicotiana Tabacum L. Leaves. Journal of Experimental Biology 2006;57(3) 547-557.

[91] Funke T, Han H, Fried MLH, Fischer M, Schonbrünn E. Molecular Basis for the Herbicide Resistance of Roundup Ready Crops. Proceedings of the National Academy of Sciences of the United States of America 2006;103(35) 13010-13015.

[92] Natarajan S, Xu C, Caperna TJ, Garrett WM. Comparison of Protein Solubilization Methods Suitable for Proteomic Analysis of Soybean Seed Proteins. Analytical Biochemistry 2005;342 214-220. 
[93] Natarajan S, Xu C, Bae H, Bailey BA, Cregan P, Caperna TJ, Garrett WM, Luthria D. Proteomic Analysis of Glycin Subunits of Sixteen Soybean Genotypes. Plant Physiology and Biochemistry 2007;45(6-7) 436-444.

[94] Sussulini A, Souza GHMF, Eberlin MN, Arruda MAZ. Comparative Metallomics for Transgenic and Non-Transgenic Soybeans. Journal of Analytical Atomic Spectrometry 2007;22(12) 1501-1506.

[95] Mounicou S, Szpunar J, Lobinski R. Metallomics: The Concept and Methodology. Chemical Society Reviews 2009;38(4) 1119-1138.

[96] Szpunar J. Advances in Analytical Methodology for Bioinorganic Speciation Analysis: Metallomics, Metalloproteomics and Heteroatom-Tagged Proteomics and Metabolomics. Analyst 2005;130(4) 442-465.

[97] Mounicou S, Lobinski R. Challenges to Metallomics and Analytical Chemistry Solutions. Pure and Applied Chemistry 2008;80(12) 2565-2575.

[98] Garcia JS, Magalhães CS, Arruda MAZ. Trends in Metal-Binding and Metalloproteins Analysis. Talanta 2006;69(1) 1-15.

[99] Sanz-Mendel A, Montes-Bayón M, Sánchez MLF. Trace Elements Speciation by ICPMS in Large Biomolecules and its Potential for Proteomics. Analytical and Bioanalytical Chemistry 2003;377(2) 236-247.

[100] Thomas RA. A Beginners Guide to ICP-MS. Spectroscopy 2002;17(1) 36-41.

[101] Wagner K, Racaityte K, Unger KK, Miliotis T, Edholm LE, Bischoff R, Marko-Varga G. Protein Mapping by Two-Dimensional High Performance Liquid Chromatography. Journal of chromatography A 2000;893(2) 293-305.

[102] Neue UD. HPLC Columns: Theory, Technology and Practice. New York: Wiley-VCH Inc.; 1997.

[103] Silva MAO, Mataveli LRV, Arruda MAZ. Liquid Chromatography for Biosseparations: Fundamentals, Developments and Applications. Brazilian Journal of Analytical Chemistry 2011;1(5) 234-245.

[104] Wuilloud RG, Kannankumarath SS, Caruso JA. Speciation of Nickel, Copper, Zinc and Manganese in Different Edible Nuts: a Comparative Study of Molecular Size Distribution by SEC-UV-ICP-MS. Analytical and Bioanalytical Chemistry 2004;379(3) 495-503.

[105] Mataveli LRV, Pohl P, Mounicou S, Szpunar J. A Comparative Study of Elements Concentration and Binding in Transgenic and Non-Transgenic Soybeans Seeds. Metallomics 2010;2(12) 800-805.

[106] Koplik R, Pavelková H, Cincibuchová J, Mestek O, Kvasnicka F, Suchánek M. Fractionation of Phosphorus and Trace Elements Species in Soybean Flour and Common White Beans by Size Exclusion Chromatography-Inductively Coupled Plasma Mass Spectrometry. Journal of Chromatography B 2002;770(1-2) 261-273. 
[107] Chan Q, Caruso JA. A Metallomics Approach Discovers Selenium-Containing Proteins in Selenium-Enriched Soybeans. Analytical and Bioanalytical Chemistry 2012;403(5) 1311-1321.

[108] Chan Q, Afton SE, Caruso JA. Selenium Speciation Profiles in Selenite-Enriched Soybean (Glycine Max) by HPLC-ICPMS and ESI-ITMS. Metallomics 2010;2(2) 147-153.

[109] dos Santos Neto AJ. Multidimensional Liquid Chromatography and Tandem Mass Spectrometry for the Direct Analysis of Drugs in Biofluids: from the Conventional to the Miniaturized Scale. PhD thesis. University of São Paulo; 2007.

[110] Stroink T, Ortiz MC, Bult A, Lingeman H, de Jong JG, Underberg WJM. On-Line Multidimensional Liquid Chromatography and Capillary Electrophoresis Systems for Peptides and Proteins. Journal of Chromatography B 2010;817(1) 449-466.

[111] Lobinski R, Schaumlöffel D, Szpunar J. Mass Spectrometry in Bioinorganic Analytical Chemistry. Mass Spectrometry Reviews 2006;25(2) 255-289.

[112] Ouerdane L, Mari S, Czernic P, Lebrun M, Lobinski R. Speciation of Non-Covalent Nickel Species in Plant Tissue Extracts by Electrospray Q-TOFMS/MS after their Isolation by 2D Size Exclusion-Hydrophilic Interaction LC (SEC-HILIC) Monitored by ICP-MS. Journal of Analytical Atomic Spectrometry 2006;21(7) 676-683.

[113] Mounicou S, Szpunar J, Lobinski R, Andrey D, Blake CJ. Bioavailability of Cadmium and Lead in Cocoa: Comparison of Extraction Procedures Prior to Size-Exclusion Fast-Flow Liquid Chromatography with Inductively Coupled Plasma Mass Spectrometric Detection (SEC-ICP-MS). Journal of Analytical Atomic Spectrometry 2002;17(8) 880-886.

[114] Mataveli LRV, Fioramonte M, Gozzo FC, Arruda MAZ. Improving Metallomics Information Related to Transgenic and Non-Transgenic Soybean Seeds Using 2DHPLC-ICP-MS and ESI-MS/MS. Metallomics 2012;4(4) 373-378.

[115] Cozzolino R, de Giulio B. Application of ESI and MALDI-TOF-MS for Triacylglycerols Analysis in Edible Oils. European Journal of Lipid Science and Technology 2011;113(2) 160-167.

[116] Pessôa GS, Pilau EJ, Gozzo FC, Arruda MAZ. Ion Mobility Mass Spectrometry: an Elegant Alternative Focusing on Speciation Studies. Journal of Analytical and Atomic Spectrometry 2011;26(1) 201-206.

[117] Elliot MH, Smith DS, Parkera CE, Borchers, C. Current Trends in Quantitative Proteomics. Journal of Mass Spectrometry 2009;44(12), 1637-1660.

[118] Rodríguez-Cea A, de la Campa MRF, Alonso, IG, Sanz-Medel A. The Use of Enriched $111 \mathrm{Cd}$ as Tracer to Study De Novo Cadmium Accumulation and Quantitative Speciation in Anguilla Anguilla Tissues. Journal of Analytical and Atomic Spectrometry 2006;21(3) 270-278. 
[119] Vanhaecke F., Balcaen L., Taylor P. Use of ICP-MS for Isotope Ratio Measurements. In: Hill S.J. (ed.) Inductively Coupled Plasma Spectrometry and its Applications. Oxford: Blackwell Publishing; 2007. p160-225.

[120] Vanhaecke F, Balcaen L, Malinovsky, D. Use of Single-Collector and Multi-Collector ICP-Mass Spectrometry for Isotopic Analysis. Journal of Analytical and Atomic Spectrometry 2009;24(7) 863-886.

[121] Wu B, Zoriy M, Chen Y, Becker JS. Imaging of Nutrient Elements in the Leaves of Elsholtzia Splendens by Laser Ablation Inductively Coupled Plasma Mass Spectrometry (LA-ICP-MS). Talanta 2009;78(1) 132-137.

[122] Vanhaecke F., Kyser K. The Isotopic Composition of the Elements. In: Vanhaecke F., Degryse, P. (ed.) Isotopic Analysis: Fundamentals and Application Using ICP-MS. Weinheim: Wiley VCH; 2012. p1-29. 
